\title{
DESIGNING OF PROGRAMMABLE LOGIC CONTROLLER FOR INTELLIGENT POWER SAVING SYSTEM
}

\author{
Zhenjie Ding ${ }^{*}$, Zhengxing Zhang ${ }^{2}$, Viet Hung Luu ${ }^{3}$ \\ ${ }^{1}$ Bozhou Vocational and Technical College Bozhou 236800, China \\ ${ }^{2}$ Hefei Juhui Information Technology Co., Ltd., Hefei 230031, China \\ ${ }^{3}$ Maritime College No. 1, Haiphong, Vietnam \\ Email: zhenjied800@163.com
}

\begin{abstract}
To study the control system of lights in an intelligent power-saving circuit, a Programmable Logic Controller (PLC)-based intelligent street light control system is proposed. At the same time, the communication protocol among the host computer, concentrator, and node controller is designed. Finally, the function realizations of the host computer, centralized controller, and node controller are analyzed in depth. The results show that lights in the intelligent powersaving circuit integrate 3G communication, power line carrier communication, Geographic Information System (GIS) geographic location system, and other technologies, which can realize the grouping, broadcasting, and single node classification control of remote street lights. Also, the system can actively report abnormalities, and the host computer system provides fine visual street light operation interfaces, making the management of city street lighting more intelligent. Therefore, the designed intelligent power-saving circuit light control system has the characteristics of simple and secure operations and convenient maintenance. The collected information of various sensing devices is used as a fuzzy input reference quantity to carry out fuzzy logic analysis and intelligently control the street lighting levels, thereby realizing the purpose of energy-saving and intelligent lighting. Thus, the energy waste caused by excessive brightness is avoided, a higher level of energy-saving is realized, the more precise control is achieved, and the management level of urbanized street lights is greatly improved.
\end{abstract}

Keywords: Intelligent Power Saving, PLC, Control System, Light Attenuation Compensation, Street Light Power-Saving.

\section{Introduction}

With the development of science and technology, the population is continually exploding every corner of the world. At present, about half of the world's population lives in cities. With such a continuously growing trend, the value is estimated to reach about $70 \%$ by 2050 . Rapid population growth undoubtedly raises new challenges in urban management, resource management, and the environment, especially in terms of efficient energy management [1]. Lighting electricity consumption has accounted for $19 \%$ of global electricity consumption; in China, this figure has also reached around $12.8 \%$.

According to official statistics, in 2018, China's electricity consumption of entire society reached 6.85 trillion kilowatt hours $(\mathrm{kW} / \mathrm{h})$ (specifically 684.9 billion $\mathrm{kW} / \mathrm{h}$ ), with an increase of $8.5 \%$ yearon-year. According to the 1.4 billion population, the per capita electricity consumption is $4,889 \mathrm{~kW} / \mathrm{h}$, and the average monthly power is $407.4 \mathrm{~kW} / \mathrm{h}$ [2].

Therefore, the social and environmental burden caused by lighting electricity consumption is huge, and the task of energy conservation and emission reduction is also extremely urgent.

The design of future street lights needs to be carried out from two aspects of energy saving and street light management. By using low-energy street light equipment, such as Light Emitting Diode (LED), more than $80 \%$ of electricity in the same situation can be saved according to data analysis. Meanwhile, through proper adjustment and control of the brightness and lighting rate parameters of street lights, the power saving can reach more than $30 \%$, which significantly reduces energy consumption and management costs of street lights. Moreover, intelligent lighting has energy-saving functions, and a reasonable and effective way which can improve the technical efficiency of lighting equipment [3].

The street light has a motion detection function for environmental factors, such as people and vehicles. When the environmental parameters exceed the trigger threshold set by the system, the system will perform certain brightness adjustments and delayed lighting actions regarding the preinstalled program, which significantly saves electricity and reduces energy consumption. 
This study explores the design and implementation of a Programmable Logic Controller (PLC)-based control system for lights in the intelligent circuit. Through in-depth analysis and research on PLC communication technology and other networking technologies, the reliability, ease of operation, and overall cost of the system are analyzed. In terms of designing a communication protocol for intelligent power-saving lighting control after selecting a PLC scheme, the bandwidth utilization of the system is effectively improved, the error rate of data control is reduced, the control rate increases and the traffic overhead caused by control communication is reduced.

\section{Methods}

\subsection{Overall architecture of intelligent street light control system}

The intelligent power-saving circuit light system is mainly composed of a sensing layer, a data processing layer, and an application layer. The sensing layer is mainly composed of street lights, node controllers, and sensors.

The node controller is used to control on / off status of street lights, as well as adjusting the brightness.
The sensors mainly include light sensors and vehicle sensors [4]. A centralized controller is set in the power distribution cabinet in a road section, which is used to collect the data of all street lights in the road section. The centralized controller and the node controller use the power carrier to communicate. The data processing layer mainly includes a centralized controller, a server, and a transmission network. The server is generally deployed in the data center computer room and connected to the centralized controller through an Ethernet or General Packet Radio Service (GPRS) wireless network.

The server can receive the data of the centralized controller and can also send control commands to the concentrator, which is a two-way communication process [5]. The application layer is mainly the user application center, which usually includes PCs, tablet computers, and smartphones. Users connect to the server through smart terminals to monitor street lights.

Figure 1 shows a classic architectural diagram of a smart circuit light control system.

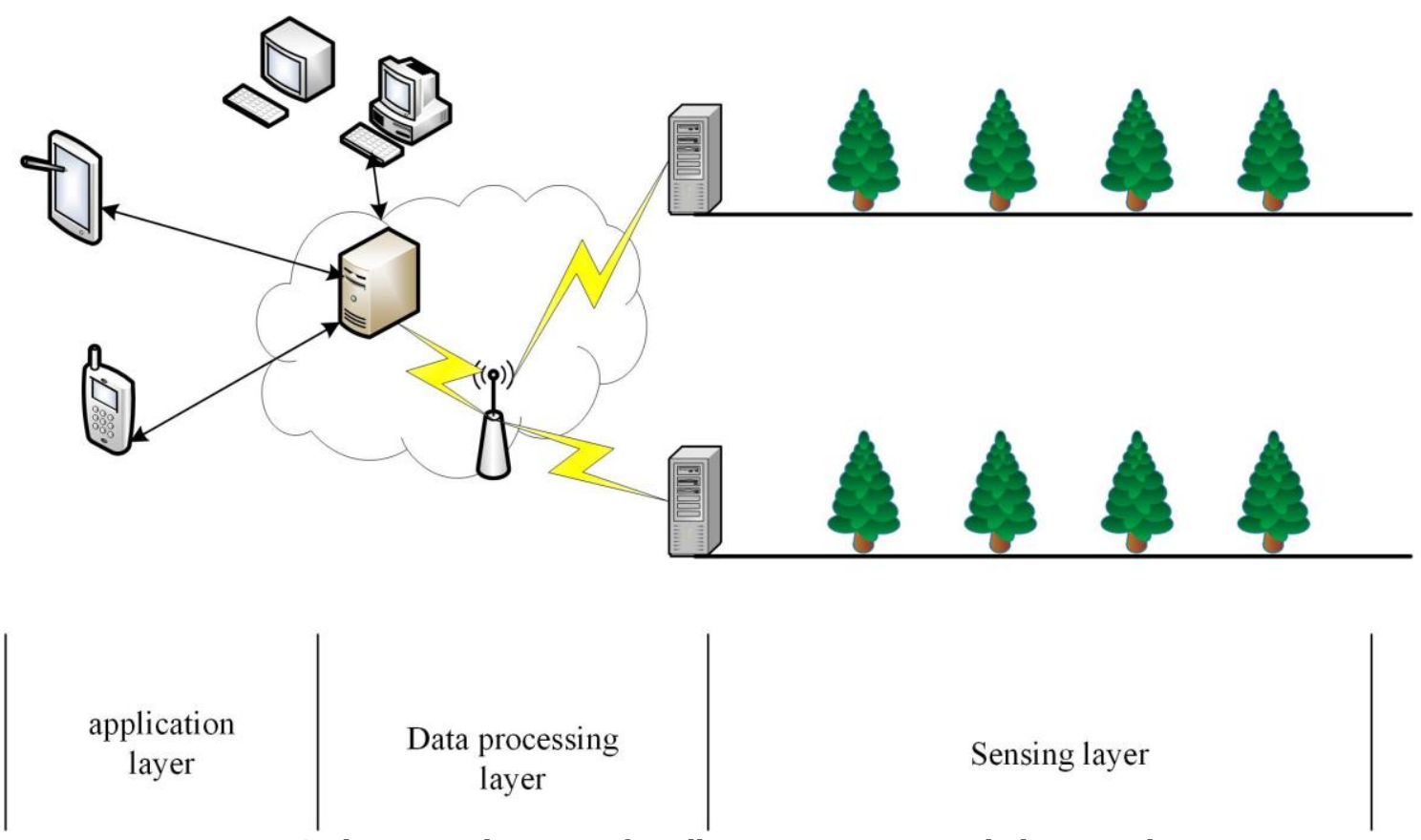

Figure 1: Architecture diagram of intelligent section circuit light control system

As shown in the above figure, the server assumes the role of a control center in the street light system. Each task requires the server to send instructions to the concentrator, such as the electric power of a remote street light node and other parameters.

The identifier is stored in the queue; then, the parameters such as node current and voltage are copied to the server by polling for related processing. Traditional street light control operations are the most common type of system operation. The remote control of street lights is mostly based on the data of the actual state of the street lights. Data fluctuations in node operation are 
often fluctuations within the allowable range. In the filtering processing method, the server uses a wide area network or a wireless network to establish a communication link with the concentrator; thus, the control update loses substantial significance, which wastes a lot of wired and wireless communication traffic [6]. Constrained by the slower PLC communication transmission rate, the batch control time has a considerable delay. The large unfiltered data occupies the communication channel resources, and there are more control deviations. According to the actual test and statistics of the system, the batch control accuracy of the traditional street light control management system is to account only $86.7 \%$.

\section{$2.2 \quad$ Interaction protocol concentrator and host computer \\ between}

The host computer and the concentrator establish a TCP/IP connection through a local area network or a CDMA, WCDMA, or GPRS wireless network. The control code (part $C$ of the data frame header) of the smart street light control system communication protocol can indicate different types of operations, including concentrator configuration, single light control, group control, and broadcast control operations. The following Table 1 is the functions corresponding to the control codes in the communication protocol frame and the control direction of the protocol.

Table 1. Interaction protocol between concentrator and host computer

\begin{tabular}{|c|c|c|c|c|c|}
\hline No. & $\begin{array}{l}\text { Control } \\
\text { codes }\end{array}$ & Functions & Transport direction & $\begin{array}{l}\text { Answer } \\
\text { codes }\end{array}$ & Remark \\
\hline \multirow[b]{2}{*}{1} & \multirow[b]{2}{*}{$00 \mathrm{H}$} & $\begin{array}{l}\text { Concentrator control or parameter } \\
\text { configuration }\end{array}$ & Host-> Concentrator & $80 \mathrm{H}$ & \\
\hline & & $\begin{array}{c}\text { Concentrator control or } \\
\text { configuration parameter results } \\
\text { returned }\end{array}$ & Concentrator-> Host & $80 \mathrm{H}$ & \\
\hline \multirow{2}{*}{2} & \multirow{2}{*}{$01 \mathrm{H}$} & $\begin{array}{l}\text { Single point control of a terminal } \\
\text { under the concentrator }\end{array}$ & Host-> Concentrator & $80 \mathrm{H}$ & On demand \\
\hline & & $\begin{array}{l}\text { Single point control results } \\
\text { returned }\end{array}$ & Concentrator-> Host & $80 \mathrm{H}$ & On demand \\
\hline \multirow{2}{*}{3} & \multirow{2}{*}{$02 \mathrm{H}$} & $\begin{array}{c}\text { Control of certain terminal groups } \\
\text { under the concentrator }\end{array}$ & Host-> Concentrator & $80 \mathrm{H}$ & Multicast \\
\hline & & $\begin{array}{l}\text { Single point results returned for } \\
\text { group control }\end{array}$ & Concentrator-> Host & $80 \mathrm{H}$ & Multicast \\
\hline \multirow[t]{2}{*}{4} & \multirow{2}{*}{$03 \mathrm{H}$} & $\begin{array}{l}\text { Broadcast control of certain types } \\
\text { of terminals under the } \\
\text { concentrator }\end{array}$ & Host-> Concentrator & $80 \mathrm{H}$ & Broadcast \\
\hline & & $\begin{array}{l}\text { Single point results returned for } \\
\text { broadcast control }\end{array}$ & Concentrator-> Host & $80 \mathrm{H}$ & Broadcast \\
\hline 5 & $04 \mathrm{H}$ & $\begin{array}{l}\text { A terminal under the concentrator } \\
\text { actively reports data }\end{array}$ & Concentrator-> Host & $80 \mathrm{H}$ & \\
\hline 6 & $80 \mathrm{H}$ & $\begin{array}{l}\text { Response to an operation or } \\
\text { request }\end{array}$ & Concentrator-> Host & None & \\
\hline
\end{tabular}

\subsection{Concentrator and node interaction protocol}

The node and the concentrator establish a connection through PLCC power carrier communication.

The second list of command codes (CMD part of the data frame header) in the protocol frame is as follows:

\subsection{Node controller control implementation}

The node controller is the lowest-level sensing device in the system. It collects real-time information such as street light node current and voltage parameter status, provides street light short circuit protection and line fault inspection, and actively reports fault information. Figure 2 shows an architectural model of the node controller hardware of the intelligent circuit light system 
Table 2. Group control operations

\begin{tabular}{|c|c|c|}
\hline No. & Command codes & Functions \\
\hline 1 & 20 & Terminal configuration commands \\
\hline 2 & 42 & Light on command \\
\hline 3 & 43 & Light off command \\
\hline 4 & 45 & Query command \\
\hline 5 & 47 & Dimming command \\
\hline 6 & 53 & Underload alarm \\
\hline
\end{tabular}

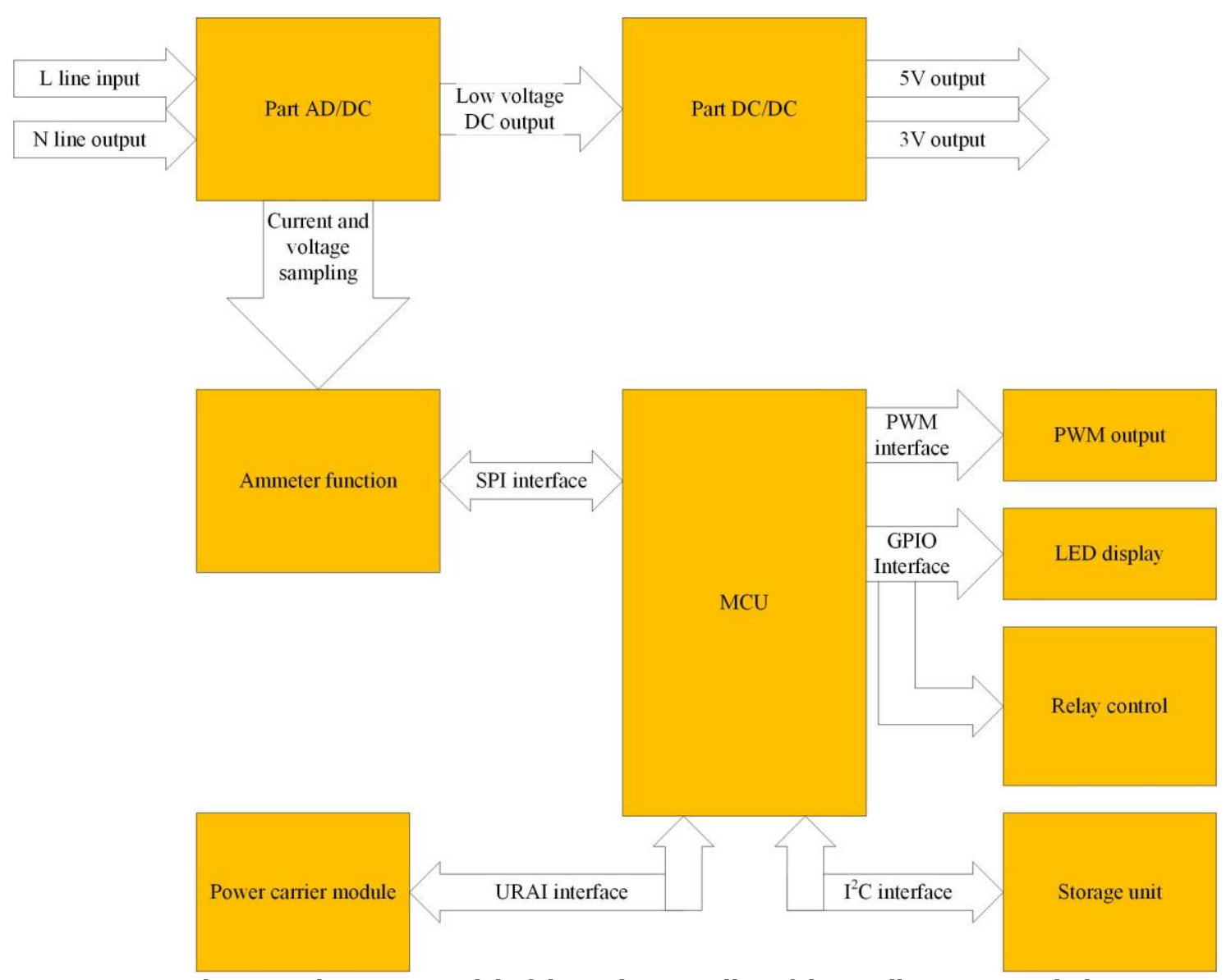

Figure 2: Hardware architecture model of the node controller of the intelligent circuit light system

Table 3. List of node controller components for intelligent section circuit light system

\begin{tabular}{|c|c|l|}
\hline No. & Function modules & \multicolumn{1}{c|}{ Specifications } \\
\hline 1 & $\begin{array}{c}\text { Inter-board } \\
\text { communication } \\
\text { processing module }\end{array}$ & $\begin{array}{l}\text { STC12LE5A602-35I, following the communication data format to } \\
\text { achieve communication control with RISE3501 }\end{array}$ \\
\hline 2 & I2C function module & Realizing the reading and storing of UID by EEPROM \\
\hline 3 & $\begin{array}{c}\text { GPIO function } \\
\text { module }\end{array}$ & Realizing on and off control of LED lights and relay control \\
\hline 4 & PWM & Pulse width modulation to control the brightness of LED lights \\
\hline 5 & SPI & Realizing the detection of current, voltage and power of CS5463 \\
\hline
\end{tabular}

The data collection designed in this study has the requirement to collect the electrical parameters of multiple street light nodes, which uses a composition method of multiple nodes and a centralized controller. Figure 3 shows the topological structure of street light data collection for smart section circuit lights. In this collection system, the data collection terminal transmits the collected information output to the active concentrator through the power line or back to the remote server database through the USB interface. 


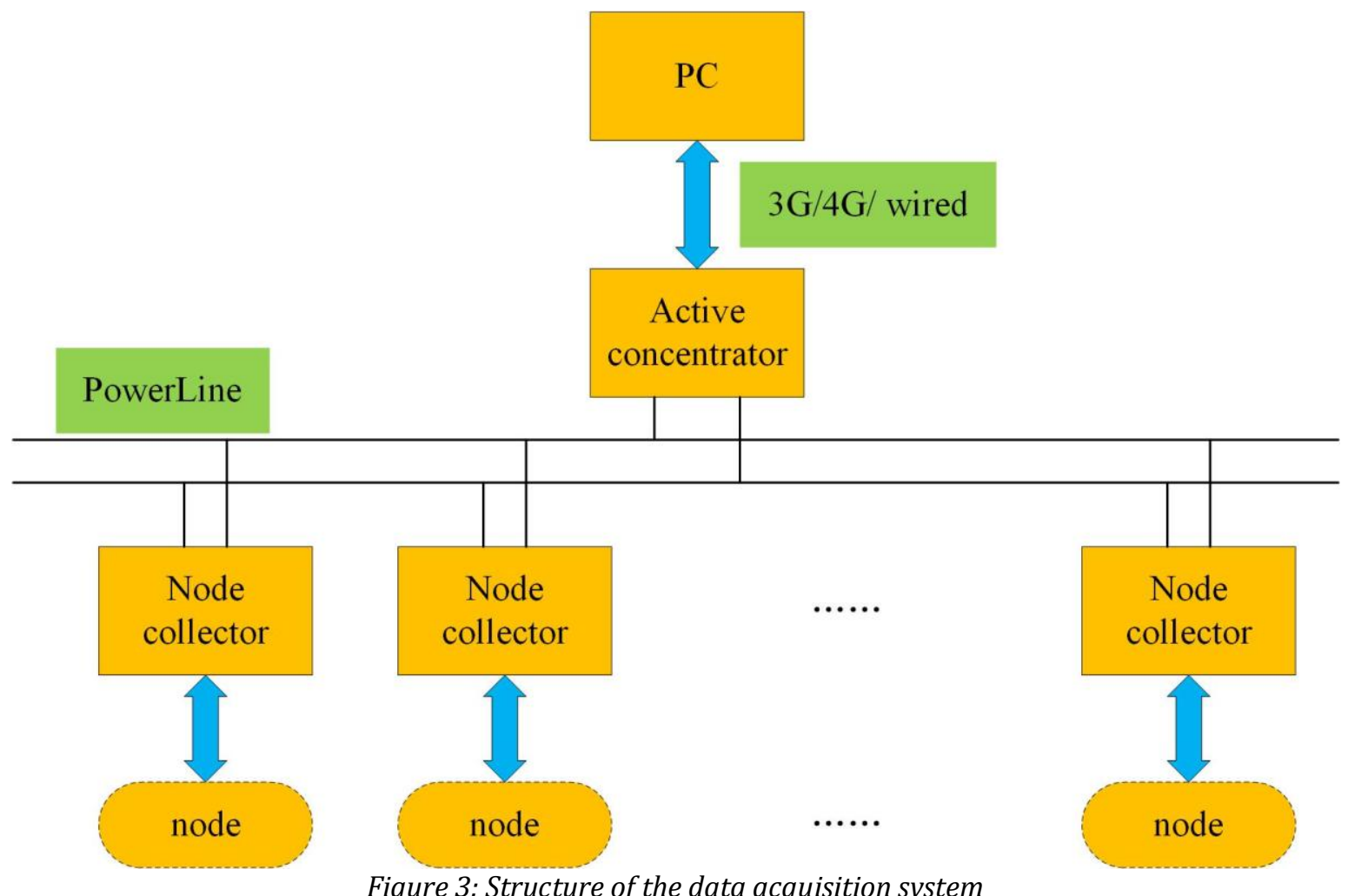

Both the node controller and the centralized controller use a single-chip STC12LE5A60S2 MCU. The STC12LE5A60S2 micro controller's analog-todigital (A/D) converter performs analog channel switching, enables sampling and data storage, and outputs it to the centralized controller of intelligent node street lights through the power carrier PLC chip [7]. The intelligent node street light node data acquisition module and the intelligent node street light concentrator module use the same circuit. They use different monitoring programs for different points. The acquisition circuit is shown in Figure 4.

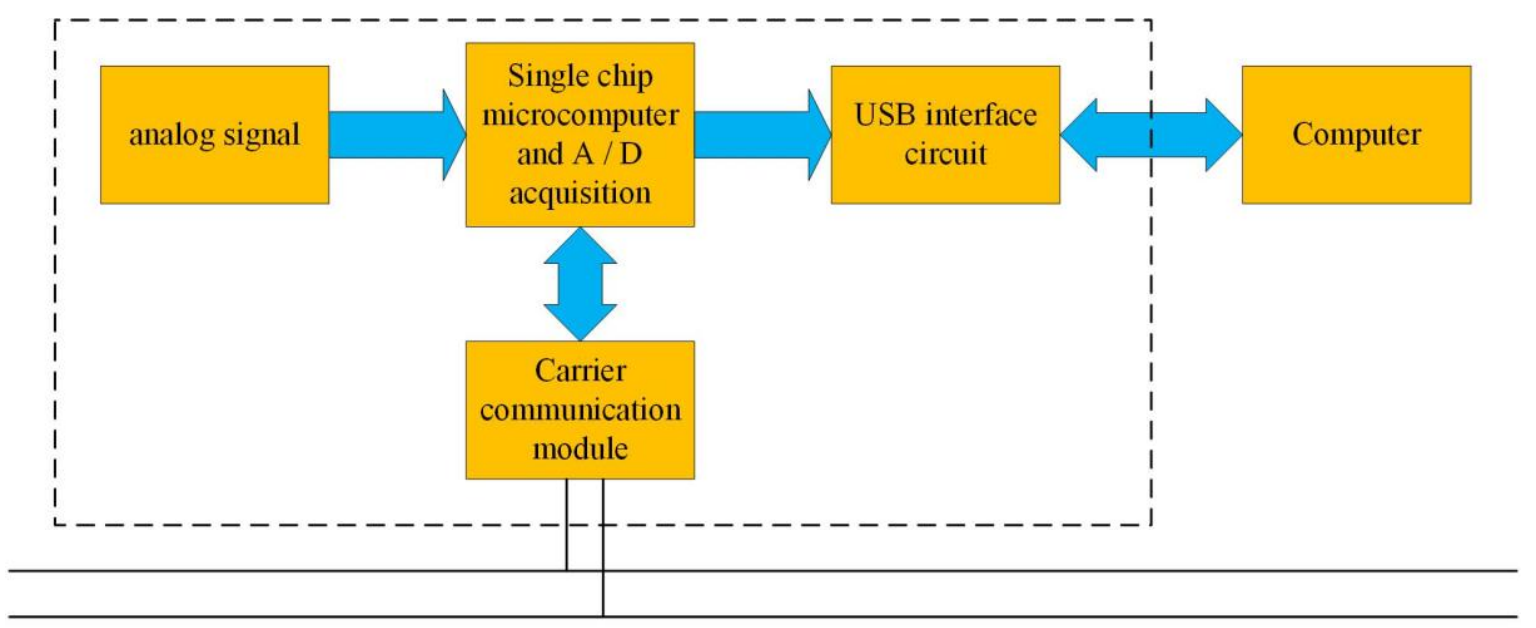

\section{PowerLine}

Figure 4: Circuit composition structure of node data collector

\section{Results and Discussions}

\subsection{Implementation of power-saving control system}

The intelligent section circuit light scheme compares data before and after the concentrator. When encountering massive changes in node status, abnormal data will be quickly reported to the backend server, and the data table data will be updated. When there is a small data status change, the concentrator will filter the upload instructions to block the data, reducing the concentrator and server. The communication load and traffic between the concentrator data filtering flowchart is shown in Figure 5: 

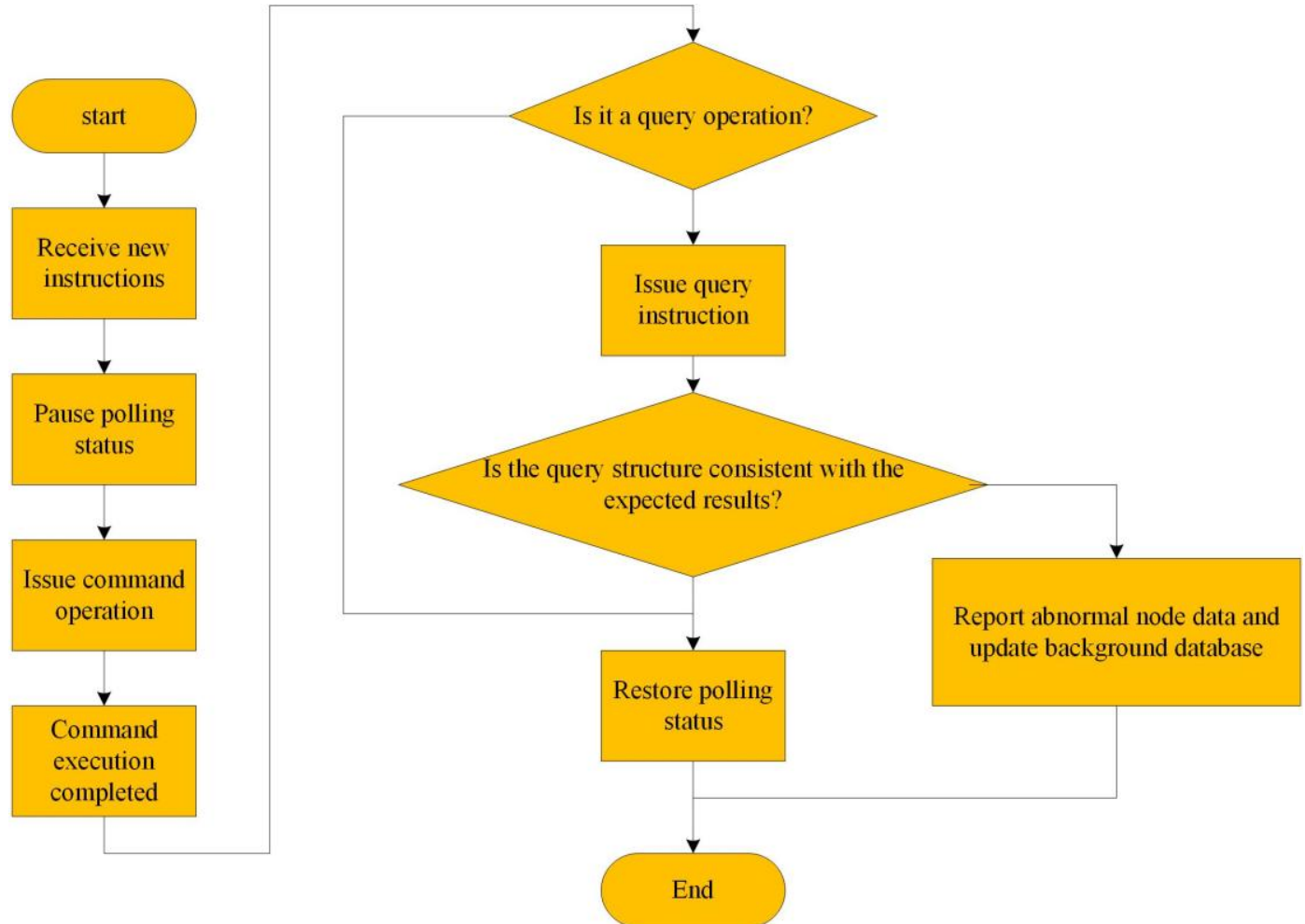

Figure 5: Concentrator data filtering

The goal of hardware design is to minimize the total cost of the entire light and maximize the utilization of electrical energy. The measurement accuracy of the light attenuation compensation control module containing various sensors is an accuracy guarantee for the actual energy saving effect. Long-term active sensors will increase energy consumption and reduce the sensor's life cycle, thereby reducing the sensor life [8]. Therefore, a long-term active sensor will increase the possibility of system failure, including the light attenuation compensation control module.
It is imperative to choose the sensors of the energy management lighting control system and light attenuation compensation control module reasonably.

Therefore, the reasonable use of wireless networks is an effective way to reduce sensor failures. Network data analysis is used to solve small changes in the external environment.

The sensor is activated only when the external environment is large or complicated. The hardware structure is shown in Figure 6.

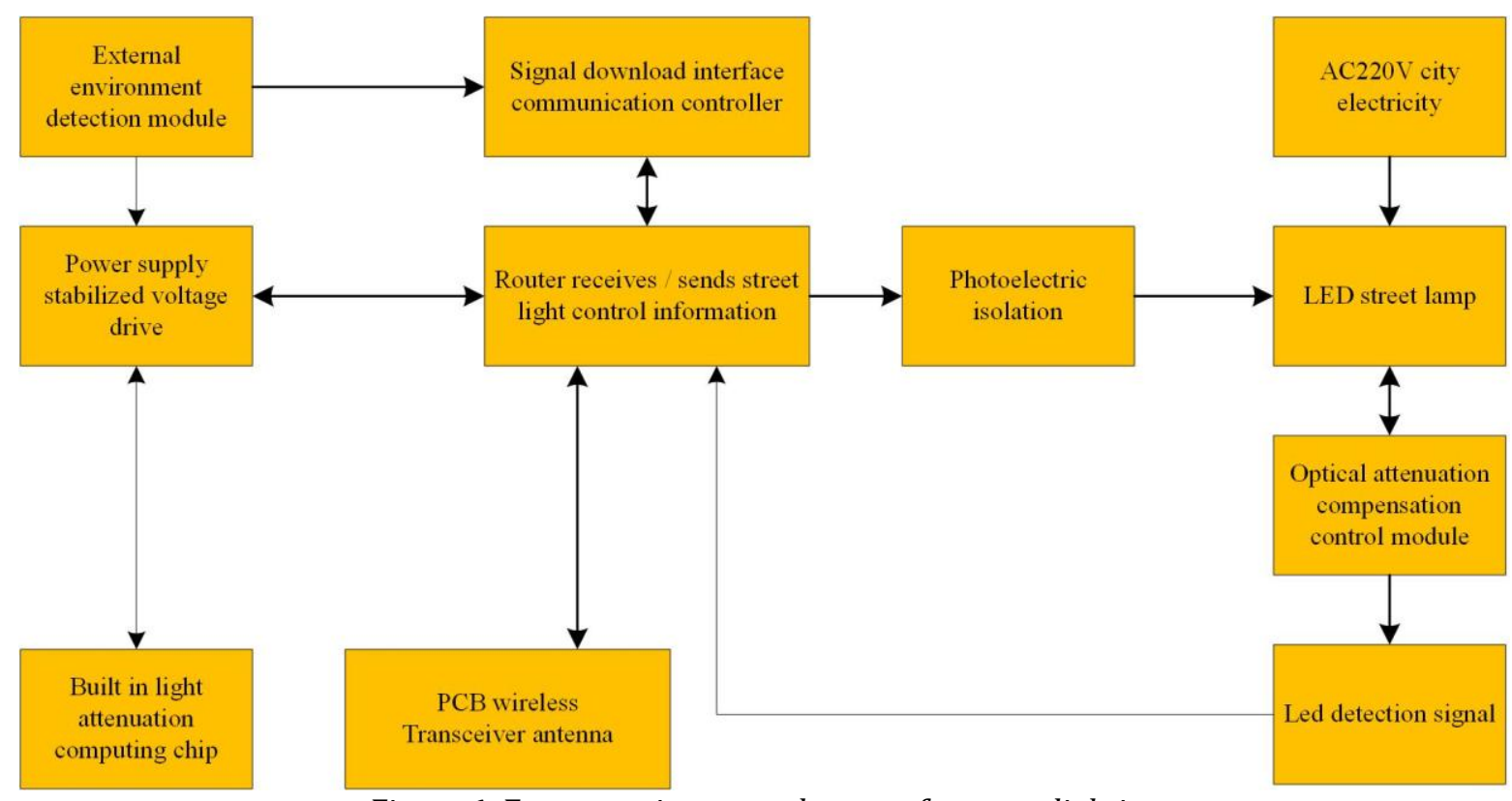

Figure 6: Energy saving control system for street lighting 
To solve the problem of energy saving and longevity of the system, it is necessary to apply the wireless sensor network to the power-saving lighting control including the light attenuation compensation control module reasonably. The wireless system includes two types of architectures, i.e., centralized and distributed. The system transmits information to the control center via the network to calculate the optimized data, thereby improving the uniformity of the lighting intensity and road surface illuminance distribution, as well as user satisfaction [9]. Based on the needs of street lighting, the external lighting effect is adjusted according to the implementation of internal and external sensors. Each sensor module uses energy-saving sensors to reduce energy consumption from each component.

\subsection{Technical and economic analysis of the system}

The photodiode LED street lighting has been widely implemented in recent years, but few studies have evaluated its energy saving economics after installation. This evaluation can test whether the research investigation conforms to the rationality of LED road lighting in terms of traffic safety and the rationality of design specifications, as well as verifying the feasibility of energy efficiency improvements. Combined with the average brightness of the street surface and the overall brightness uniformity, the longitudinal brightness uniformity, the power density, and the average illuminance are compared.
The comparison is performed under the energysaving percentage to the energy-saving value of the existing lighting control [10].

According to reports submitted by consulting companies, the annual energy cost of 340 million street lights may reach 23.9 to 42.5 billion USD by 2025. These numbers reveal incentives for research to optimize lighting efficiency and reduce energy consumptions. Due to the scale effect of street lights, even a small unit improvement can bring great benefits.

Developing static and dynamic lighting solutions makes street lighting installations energy efficient. It not only obtains the energy-saving effect obtained by replacing conventional lights such as high-pressure sodium lights with LED but also improves energy quality by introducing static and dynamic street lighting control. These two methods prove that a logical algorithm for optimal configuration is feasible, especially for large projects.

The purpose of this study is to propose solutions and processes for solving problems, which are based on the application of static and dynamic algorithms. They provide ways to scale and expand energy savings in a city using optimized lighting installations [11-14].

Studies have shown that due to the application of proposed method, a lighting system can be designed with energy consumption reductions of up to $70 \%$, as shown in Table 4.

Table 4. Comparison of energy saving data of 200W-LED street lights

\begin{tabular}{|c|c|c|c|c|c|}
\hline $\begin{array}{c}\text { Control method } \\
\text { (year) }\end{array}$ & $1 \mathrm{y} / \mathrm{kWh}$ & $2 \mathrm{y} / \mathrm{kWh}$ & $3 \mathrm{y} / \mathrm{kWh}$ & $4 \mathrm{y} / \mathrm{kWh}$ & $5 \mathrm{y} / \mathrm{kWh}$ \\
\hline $\begin{array}{c}\text { Conventional time- } \\
\text { based control }\end{array}$ & 730 & 730 & 730 & 730 & 730 \\
\hline $\begin{array}{c}\text { Static light } \\
\text { attenuation } \\
\text { compensation }\end{array}$ & 680 & 690 & 700 & 710 & 720 \\
\hline $\begin{array}{c}\text { Dynamic light } \\
\text { attenuation } \\
\text { compensation }\end{array}$ & 670 & 680 & 685 & 700 & 710 \\
\hline $\begin{array}{c}\text { Total static/dynamic } \\
\text { savings }\end{array}$ & $50 / 60$ & $40 / 50$ & $30 / 45$ & $20 / 10$ & $10 / 10$ \\
\hline
\end{tabular}

As shown in Table 4, the power-saving effect of dynamic light attenuation compensation is the most obvious. The power saving-effect of both methods decreases with time to the later period, indicating that it is necessary to rely on the compensation power to adjust the LED illumination, thereby reaching the standard value. This also requires achieving the optimal illuminance based on ensuring the energy saving of the LED, i.e., the street light is the standard illuminance value in real-time.

Based on this requirement, the average illuminance values of the three control methods for each of the five years are obtained. The actual luminous brightness is used to make an optimized comparison, as shown in Table 5. 
Table 5. 200W-LED street light illumination data comparison

\begin{tabular}{|c|c|c|c|c|c|}
\hline $\begin{array}{c}\text { Control method } \\
\text { (year/Lx) }\end{array}$ & $1 \mathrm{y} / \mathrm{Lx}$ & $2 \mathrm{y} / \mathrm{Lx}$ & $3 \mathrm{y} / \mathrm{Lx}$ & $4 \mathrm{y} / \mathrm{Lx}$ & $5 \mathrm{y} / \mathrm{Lx}$ \\
\hline $\begin{array}{c}\text { Conventional time- } \\
\text { based control }\end{array}$ & 38 & 36 & 32 & 30 & 28 \\
\hline $\begin{array}{c}\text { Static light attenuation } \\
\text { compensation }\end{array}$ & 32 & 35 & 33 & 31 & 31 \\
\hline $\begin{array}{c}\text { Dynamic light } \\
\text { attenuation } \\
\text { compensation }\end{array}$ & 32 & 32 & 32 & 32 & 32 \\
\hline
\end{tabular}

As shown in Table 5, the illumination intensity of the conventional time-controlled luminaries in the early stage of the installation will cause severe decay in the later stage. The static light attenuation compensation can achieve the expected effect in the early stage. The intermediate stage cannot meet the standard illumination due to various external environmental variables and self-junction temperature. This also causes the illumination to decline in the later stage, but it is still more controllable compared to conventional methods. The dynamic light attenuation compensation can reach the standard illuminance value every year due to various intervention measures.

\section{Analysis of system power-saving effect}

The data analysis is based on the user power statistics from January 2017 to December 2017, and from January 2018 to December 2018, as shown in Figure 7 below. During the peak power consumption period in summer, the total power consumption in June 2017 and June 2018 decreased from $8336 \mathrm{kWh}$ to $6370 \mathrm{kWh}$, with a decrease of $1966 \mathrm{kWh}$. During the peak power consumption period in winter, the total power consumption in 2017 and December 2018 dropped from $7872 \mathrm{kWh}$ to $5459 \mathrm{kWh}$, with a reduction of $2413 \mathrm{kWh}$. Therefore, the electricity consumption of users has significantly decreased before and after the implementation of time-sharing control, which can save electricity expenses of 8361 CNY throughout the year.

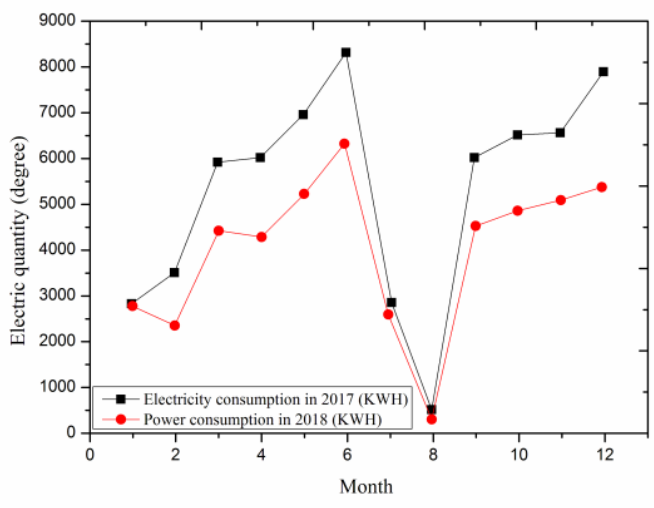

Figure 7: Power consumption statistics before and after time-sharing control
Based on the statistics of street lamp power consumption from January 2017 to December 2017, and from January 2018 to December 2018, the comparison is shown in Figure 8 below. In the case of short days and long nights in winter, the total power consumption in November 2017 and November 2018 decreased from $2236 \mathrm{kWh}$ before light control to $1028 \mathrm{kWh}$, with a decrease of 1208 $\mathrm{kWh}$; the total power consumption in December 2017 and 2018 decreased from $2367 \mathrm{kWh}$ to 1039 $\mathrm{kWh}$, with a decrease of $1328 \mathrm{kWh}$. Therefore, the electricity consumption of street lights before and after the implementation of light intensity control has decreased significantly, which can save about 7,367 CNY in electricity expenses throughout the year.

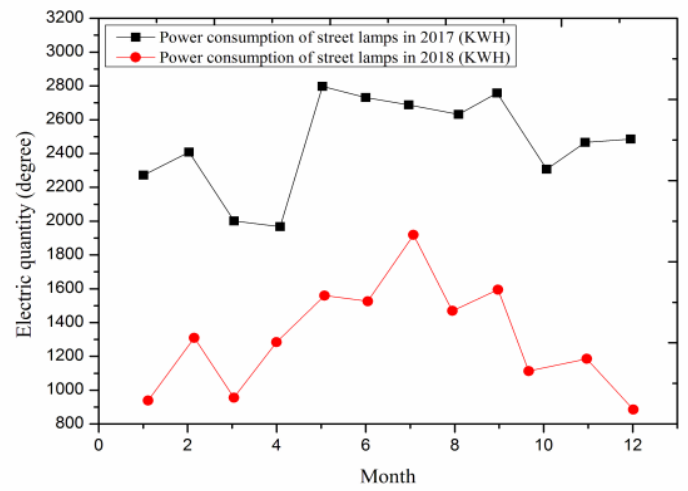

Figure 8: Power consumption statistics of street lights before and after illumination control

\section{Conclusions}

The intelligent circuit light system based on PLC designed in this study has a stable and practical upper computer system, which can easily manage, monitor, and control the remote street lights. The system has better energy saving efficiency than ordinary street lights. Also, it can quickly respond to abnormal conditions of failure and has high maintenance efficiency. Through three levels of design, the human-machine control can be better realized. Different types of operations on the street lamp area, line, and node can be implemented in detail. 
Street lights can actively report the abnormalities, such as line overload, cable disconnection, and theft. Adopting advanced client software technology and scientific modular programming, the host computer system of intelligent circuit lights has an excellent interface aesthetics, which greatly facilitates the remote control of street lights. The maneuverability and reliable connection of the concentrator and node controller can meet the basic needs of intelligent control. However, careful considerations are still inadequate, and there is still potential for further improvement. To meet the complex challenges of urbanization management and to promote the goal of urban streetlight management, the key considerations for the next stage of the intelligent section circuit light control system are analyzed. Since the intelligent section circuit light system adopts the power carrier communication method, the rate of the system has been inherently restricted. The frequency bandwidth of the power carrier channel is only within the range of $3 \mathrm{kHz}$ to $500 \mathrm{kHz}$, and the bandwidth resources are limited. During the transmission process, as the transmission distance is affected by noise, the control fails, or the street light information is collected incorrectly. The street light system has not yet passed the overall performance test. There is no transmission impedance, signal attenuation, and transmission distance for noise quantitative analysis of changes. The subsequent study needs to explore the influence of channel factors on system reliability further.

\section{References}

[1] Xin J, Kaixuan Z, Jiangtao J, et al. Design and implementation of Intelligent transplanting system based on photoelectric sensor and PLC. Future Generation Computer Systems, 2018, 88, pp. 127-139.

[2] Yılmaz C, Yılmaz E N, Işık M F, et al. Design and implementation of real-time monitoring and control system supported with IOS/Android application for industrial furnaces. IEEJ Transactions on Electrical and Electronic Engineering, 2018, 13(9), pp. 1236-1244.

[3] S. Sathishkumar, Dr. M. Kannan. Topology Optimization of Integrated Combustion Engine Piston Using $\mathrm{F}$ ea Method (Cae Tools). Acta Mechanica Malaysia, 2019, 2(1): 01-05.
[4] L. Natrayan, E. Aravindaraj, M.S. Santhosh, M. Senthil Kumar. Analysis and Optimization of Connecting Tie Rod Assembly In Agriculture Application. Acta Mechanica Malaysia, 2019, 3(1): 06-10.

[5] Rohit Rana, Rajendra Kumar. Performance Analysis of Aodv In Presence of Malicious Node. Acta Electronica Malaysia, 2019, 3(1): 01-05.

[6] Ahmed Abugalia. Effect of Corona on The Wave Propagation Along Overhead Transmission Lines. Acta Electronica Malaysia, 2019, 3(1): 0609.

[7] Muhammmad Ikram, Abbas Muhammad, Atiq Ur Rahmn. Analytic Solution To Benjamin-BonaMahony Equation By Using Laplace Adomian Decomposition Method. Matrix Science Mathematic, 2019, 3(1): 01-04.

[8] Ma M, Huang B, Wang B, et al. Development of an Energy-Efficient Smart Socket Based on STM32F103. Applied Sciences, 2018, 8(11), pp. 2276.

[9] Blanco J, García A, Morenas J. Design and Implementation of a Wireless Sensor and Actuator Network to Support the Intelligent Control of Efficient Energy Usage. Sensors, 2018, 18(6), pp. 1892.

[10] Cano Ortega A, Sánchez Sutil F J, De la Casa Hernández J. Power Factor Compensation Using Teaching Learning Based Optimization and Monitoring System by Cloud Data Logger. Sensors, 2019, 19(9), pp. 2172.

[11] Khorram M, Abrishambaf O, Faria P, et al. Office building participation in demand response programs supported by intelligent lighting management. Energy Informatics, 2018, 1(1), pp. 9.

[12] Hussain S M, Nadeem F, Aftab M A, et al. The emerging energy internet: architecture, benefits, challenges, and future prospects. Electronics, 2019, 8(9), pp. 1037.

[13] Sheng-hao F, Zhen-peng S, Long-chao W, et al. Design of Intelligent Greenhouse Monitoring and Control System based on PLC. Journal of Applied Science and Engineering Innovation, 2019, 6(1), pp. 18-21.

[14] Xu P Q, Shen M X, Liu L S, et al. Design and implementation of piggery environmental monitoring system based on ECS and WSN. Journal of South China Agricultural University, 2018, 39(1), pp. 112-119. 